\title{
Influence of Reprocessing in the Formation of Functional Groups During Low Density Polyethylene Aging
}

\author{
Maurício M. Selonke, Tiago F. Moreira, Lincon L. Schafranski, Adriane Bassani, Benjamim de M. Carvalho, Luís A. Pinheiro \\ Departamento de Engenharia de Materiais, Universidade Estadual de Ponta Grossa \\ Rosilene A. Prestes, Denise M. Almeida \\ Coordenação de Alimentos, Universidade Tecnológica Federal do Paraná, campus de Ponta Grossa
}

\begin{abstract}
In recent years, the interest in polymer recycling has increased. However, in every reprocessing step the material undergoes shear stress and is affected by temperature and oxygen. The aim of this paper is to investigate the influence of multiple extrusion in the generation of functional groups, namely hydroperoxide, carbonyl, and transvinylene. Low density polyethylene was reprocessed three times in a single screw extruder. In each recycling step hot pressed films were prepared. These films were submitted to a heat treatment in an oven with air circulation and renovation to proceed with aging tests at different times and temperatures. The results obtained showed that all functional groups had their concentration increased with the increase in number of reprocessing, the aging time and temperature of the heat treatment. The factorial design was applied to verify the influence of these parameters. All the parameters had significant effects, since their regression coefficients had the same order of magnitude, with the most influential parameter being the aging temperature, followed by the aging time and number of extrusions. Most of the interactions were influential, indicating that the formation of functional groups depends upon their interaction, and not only on their isolated effects.
\end{abstract}

Keywords: Low density polyethylene, multiple extrusions, factorial design, functional groups formation.

\section{Introduction}

Low density polyethylene (LDPE) is an important commodity polymer because of features like low cost, toughness and rheological behavior suitable to a plenty of processes ${ }^{[1]}$. Because of it, LDPE is one of the most polymers used mainly for food, cosmetics, drugs, pipes, and agricultural aplications. Its widely using leads to great amounts of polymer discarded in environment, littering it. Reprocessing is one reasonable alternative to reuse LDPE and other polymers ${ }^{[2]}$. The most common way to provide it is by extrusion, in a method called mechanical recycling; however, this process subjects the polymer to a set of degradations: mechanical by shear stress, thermal by the action of temperature, and oxidative because of the presence of oxygen ${ }^{[3-6]}$. Besides this, all polymeric material is subjected to a set of degradative agents, like electromagnetic radiations, temperature and chemicals, not only in processing step, but during all its life cycle.

The degradative process begins with formation of alkyl radicals due to parameters like temperature, shear stress and catalyst residue ${ }^{[7-9]}$. Oxygen availability in the system and its concentration has also an important role in the thermo-mechanical degradation ${ }^{[7-14]}$. If the concentration of oxygen is low, these macroradicals can react each other, giving rise to branching and unsaturated groups, like vinyl (Equation 1) and transvinylene groups (Equation 2); on the other hand, if oxygen is present in a high content, it will easily react with those macroradicals, resulting in the propagation of degradation processes through formation of free radicals and unstable compounds that attack the polymeric chains ${ }^{[7]}$ (Equation 3). The origin of the chain scission mechanism in polymers is due to the oxygen reaction with polymer's macromolecules, yielding alcoxi and peroxi radicals ${ }^{[8,9]}$. These radicals abstract a hydrogen atom, giving rise to the $\beta$ scission, leading to a decrease in molecular weight ${ }^{[15]}$ and formation of carbonyled end groups. The chain branching mechanisms is formed when alkyl macroradicals are added to vinyl groups, yielding at final stages crosslinked molecules ${ }^{[4,5]}$
(Equation 1). Disproportionation reaction of almost all of these radicals leads to formation of transvinylene and vinylidene groups $^{[8,16]}$ (Equation 2).

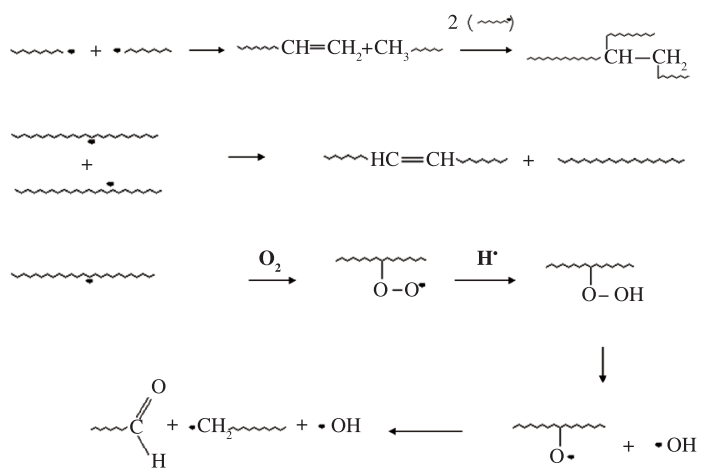

El'darov et al. ${ }^{[6]}$ verified a concurrence of degradation mechanisms for polyethylene during extrusion and the depletion of oxygen along single screw extruder length. Pinheiro, Chinelatto and Canevarolo ${ }^{[4,5]}$ observed the same behavior for HDPE during multiple extrusions in twin screw extruder and internal mixer processing. Dostál et al. ${ }^{[17]}$ suggested that the predominant mechanism of LDPE degradation during multiple extrusions is the chain scission in the early processing, followed by chain branching due to macroradicals recombination in the later stages. Moss and Zweifel ${ }^{[9]}$ studied the degradation of HDPE under multiple extrusions in a single screw extruder and observed that the Phillips' HDPE type showed an increase in molecular weight, whereas reduction was observed for the Ziegler-Natta's type. Dontula and Campbell ${ }^{[18]}$ conclude the same effect when HDPE was processed in a twin-screw extruder, following differences in viscosity of the extruded material at different temperature profiles and feeding rate. Canevarolo and Babetto ${ }^{[3]}$ studied the level of

Autor para correspondência: Luís A. Pinheiro, Department of Materials Engineering, State University of Ponta Grossa - UEPG,

Av. General Carlos Cavalcanti, 4748, CEP 84030-900, Ponta Grossa, PR, Brazil, e-mail: lapinheiro@uepg.br 
thermo-mechanical degradation when polypropylene is reprocessed in a modular twin-screw extruder as a function of the screw profile. Higher shearing profiles, assembled with kneading discs, imposed higher levels of degradation when compared to milder profiles, built only with conveying elements. Cruz and Zanin ${ }^{[19]}$ compared the melt flow indexes (MFI) and data from cone-plate rheometry for stabilized and non-stabilized reprocessed HDPE and concluded that reprocessing without stabilization leads to an increase in molar mass due to chainbranching.

Considering that reprocessing is an important step during recycling, in this work it is observed the effect of multiple extrusions in the formation and/or comsumption of functional groups during its aging experiments. For such purpose, it is used factorial design, that is a mathematical-statistic tool applied to infer the effect of parameters involved in plenty of experiments and studies, like blending ${ }^{[20]}$, hydrogels characterization ${ }^{[21]}$, mechanical properties ${ }^{[22]}$, residence time distribution during extrusion ${ }^{[23]}$, polymer functionalization ${ }^{[24]}$, and also polymer degradation ${ }^{[25,26]}$

\section{Experimental}

\section{Materials}

PB 681 low density polyethylene (LDPE) was provided by Braskem, with melting flow index of $3.5 \mathrm{~g} / 10$ minutes (ASTM 1238). The resin was used in pellet form, as received by the supplier.

\section{Extrusion process}

Material extrusion took place in a Ciola ME 30 single screw extruder, suitable for polyolefins, with temperature profile equal to $180{ }^{\circ} \mathrm{C}$ for all four heating zones. The screw speed was set at $50 \mathrm{rpm}$. As the work considers reprocessing, after being extruded the material was pelletized, $50 \mathrm{~g}$ was taken for further analysis and the other part was re-fed in the extruder hopper to reprocess the material. The total amount of reprocessing was three.

\section{Aging experiments}

Films with $150 \mu \mathrm{m}$ thickness were hot pressed at $160{ }^{\circ} \mathrm{C}$ and submitted to aging tests with air input system in order to avoid atmosphere depletion. The parameters changed were number of reprocessing, time and temperature of expositing. The temperatures tested were 50, 75, and $100{ }^{\circ} \mathrm{C}$ and the time, 100, 200, and 300 hours. Each condition was replicated twice in order to verify reproducibility.

\section{Infrared spectroscopy}

After being aged, the films were analyzed in a Nicolet 4700 spectrometer, with resolution of $2.0 \mathrm{~cm}^{-1}$ and 40 scans. In this work, it was taken the absorbances at 3410, 1720, and $965 \mathrm{~cm}^{-1}$, attributed to hydroperoxide, carbonyl, and transvinylene groups, respectively. To eliminate the effect of uneven film thickness, all absorbances were divided by that at $2017 \mathrm{~cm}^{-1}$, related to $\mathrm{CH}_{2}$ stretching and used as reference by Rideal and Padget ${ }^{[7]}$ and Pinheiro, Chinelatto and Canevarolo ${ }^{[4,5]}$, according to Equation 4.

$$
I_{v}=\frac{\mathrm{A}_{v}}{\mathrm{~A}_{2017}}
$$

where $A_{v}$ and $A_{2017}$ are the absorbance of the analyzed and $2017 \mathrm{~cm}^{-1}$ peaks, respectively. The ratio between these absorbances provides a relative concentration of hydroperoxide, carbonyl and transvinylene groups, being called here index of functional group $\left(\mathrm{I}_{v}\right)$.

\section{Factorial design methodology}

Factorial design was applied in order to get the weight of each parameter on the functional groups concentration after aging essays. The parameters values of reprocessing number, time and temperature of exposure were codificated: the lowest, medium and the highest level of each parameter were set equal to $-1,0$, and +1 , respectively. The parameters values were correlated with resultant functional group concentration for each condition calculating the coefficients of a regression equation (Equation 5) by multiple linear regression (MLR), providing empirical models that enables the knowledge of the influence of each parameter in the the changes of functional group concentrations. In Equation 5, the subindexes 1,2 , and 3 are concerned to number of reprocessing, temperature and time, respectively; the terms $b_{i}, b_{i i}, b_{i j}$, and $b_{i j k}$ are the linear, quadratic, first order interaction, and second order interaction coefficients, respectively.

$$
\begin{aligned}
\hat{y}= & b_{0}+b_{1} \cdot x_{1}+b_{2} \cdot x_{2}+b_{3} \cdot x_{3}+b_{11} \cdot x_{1}^{2}+b_{22} \cdot x_{2}^{2}+b_{33} \cdot x_{3}^{2} \\
& +b_{12} \cdot x_{1} \cdot x_{2}+b_{13} \cdot x_{1} \cdot x_{3}+b_{23} \cdot x_{2} \cdot x_{3}+b_{123} \cdot x_{1} \cdot x_{2} \cdot x_{3}
\end{aligned}
$$

The $t$ and $F$ tests were applied to verify the statistical significance of equation coefficients and statistical significance of regression, respectively, both at $95 \%$ of confidence ${ }^{[27]}$. $F$ test is achieved by the comparison of ratio between quadratic mean of regression and residue (MQR/MQr) and the corresponding value in F distribution, with the same degree of freedom for regression and residue. A regression is called statistically significant if the ratio between the quadratic means is ten times higher than value in $\mathrm{F}$ distribution ${ }^{[27]}$ (Equation 6):

$$
\frac{M Q R / M Q r}{F_{R, r}} \geq 10
$$

\section{Results and Discussion}

\section{Quantification of hydroperoxide concentration}

Figure 1 shows the variation of $3410 \mathrm{~cm}^{-1}$ peak as function of reprocessing number. It is possible to observe the increase in hydroperoxides concentration with increase in number of reprocessing. Hydroperoxide is cited on literature as the first

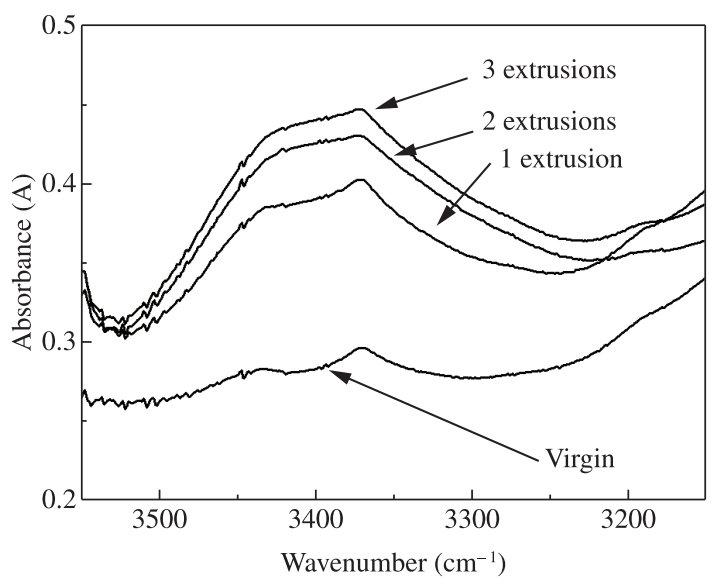

Figure 1. Hydroperoxide formation with number of reprocesses, for material aged at $100{ }^{\circ} \mathrm{C}$ and 300 hours. 
component to be formed due to polymer chain degradation, where an oxygen molecule first reacts with alkyl radical yielded due to stress or high temperature effects ${ }^{[8-9]}$. Although hydroperoxides present no free radicals, the bond between oxygen atoms are weak and made these groups quite unstable and easily dissociate in alcoxi and hydroxi radicals, which in turns react with others macroradicals formed.

As the number of reprocessing increases the hydroperoxide concentration increases being a result of the great amount of macroradicals formed due to shear stress. It provides higher number of free radicals to react with oxygen in the medium. It was also investigated if the reprocessing might possibly facilitate the formation of these groups during aging. The result of hydroperoxide concentration is plotted on Figure 2 as function of number of extrusions and temperature for 300 hours aging.

For $50{ }^{\circ} \mathrm{C}$ there is no significant increase in hydroperoxide concentration, considering either time of aging or number of recycles. At $75{ }^{\circ} \mathrm{C}$, there is a considerable increase in the concentration of this functional group from 300 hours of aging. In this temperature, the concentration of hydroperoxide increases with number of recycles, which is attributed to the increase in the number of macroradicals formed due to shear stress in the extruder. However, an increase in the temperature to $100{ }^{\circ} \mathrm{C}$ gives rise to a great increase in hydroperoxide concentration compared with the two previous temperatures. In this temperature, as seen for $75^{\circ} \mathrm{C}$, the high the number of recycles higher the number of hydroperoxide groups in the polymer chains.

At this moment a statement must be revised: first, hydroperoxide is the precursor of other functional groups related to polymer degradation. The increase in hydroperoxide is also associated with higher temperatures because it reduces the energy required for oxidation. Greaters times of exposure also leads to higher concentration of hydroperoxide because of the high period in touch with oxygen molecules. Even though, in this work it was also found that increase in number of extrusion gives rise to increase in hydroperoxide concentration. In the screw extruder, polymer undergoes severe shear stress which leads to bond rupture. This cleavage on polymer chain is responsible for the formation of free radical in the polymer macroradical and can be followed or not by chain scission. Alkyl radicals easily react with oxygen initiating the process of polymer oxidation. From these results it is possible to state that recycled polymers when subjected to temperature and time aging are more prone to undergo oxidation.

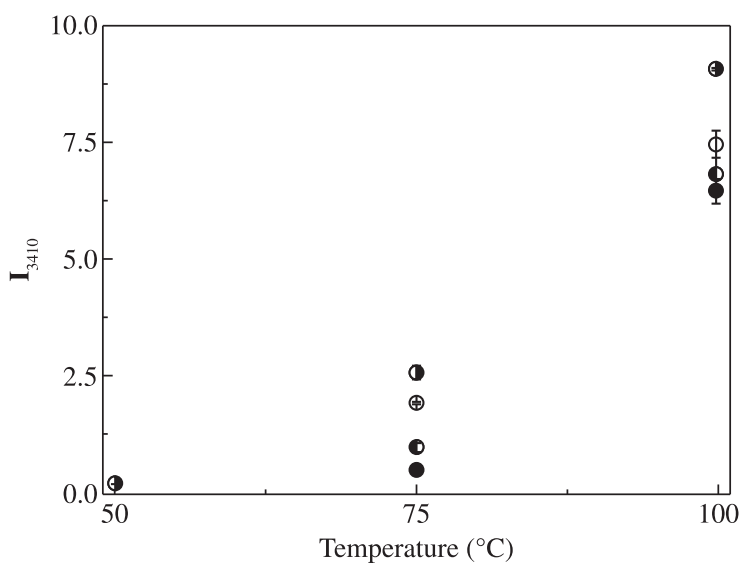

Figure 2. Hydroperoxide index as function of temperature of aging and number of reprocessing, for 300 hours: $(\bullet)$ non processed; $(\boldsymbol{D})$ processed once; (०) processed twice; ( $(\mathbf{O})$ processed three times.
In order to verify the level of influence of each parameter on hydroperoxide concentration it was performed a regression using factorial design methodology. The regression uses the codificated values of temperature, time and number of extrusions, being -1 the lowest, 0 the intermediate and +1 the highest level. Fit to experimental hydroperoxide concentration was provided by a second order polynomial considering also the first and second interactions, according to Equation 5. The coefficients found are showed in Figure 3.

In this figure, $E$ is the number of extrusion, $T$ temperature and $t$, the time. This model provided a $r^{2}=0.9832$. The value calculated for Equation 6 is equal to 128.8, which means that according $F$ test the regression is statistically significant. In the present figure it is presented as well parameters that was not considered statistically significant according to $t$ test: quadratic coefficient of $E\left(E^{2}\right)$, first order interaction between $\mathrm{T}$ and $\mathrm{t}$ (T.t), and second order interaction for the three parameters (T.t.E). Aging temperature is the most influent parameter, followed by aging time and number of reprocessing; however, the order of magnitude for all these variables is quite similar. The interactions tested E.T and T.t showed to be high. The first indicates that number of recycles is important for hydroperoxide formation, not only isolated, but together with temperature. The second are related to the kinetic development, once it translates that time and temperature interaction has a great weight in the formation of that functional group. All coefficients have positive values, which means a direct relation with hydroperoxide concentration: their increase leads to an increase in that functional group, unlike $t^{2}$ parameter.

\section{Parameters influence on carbonyl concentration}

Carbonyl groups are produced by $\beta$ - chain scisson from alcoxi radicals when oxygen atom takes an electron from a carbon-carbon or carbon-hydrogen bond. Figure 4 shows the result for carbonyl group absorption as function of number of recycles.

There is an increase in carbonyl group concentration with number of extrusions as a result of an increase in number of macroradicals formed due to chain scission that react with oxygen. It is possible to state a relation between hydroperoxide and carbonyl groups concentration, once the former leads to the production of the latter. Figure 5 shows the increase in carbonyl group concentration as function of extrusions number and temperature, for films aged for 300 hours.

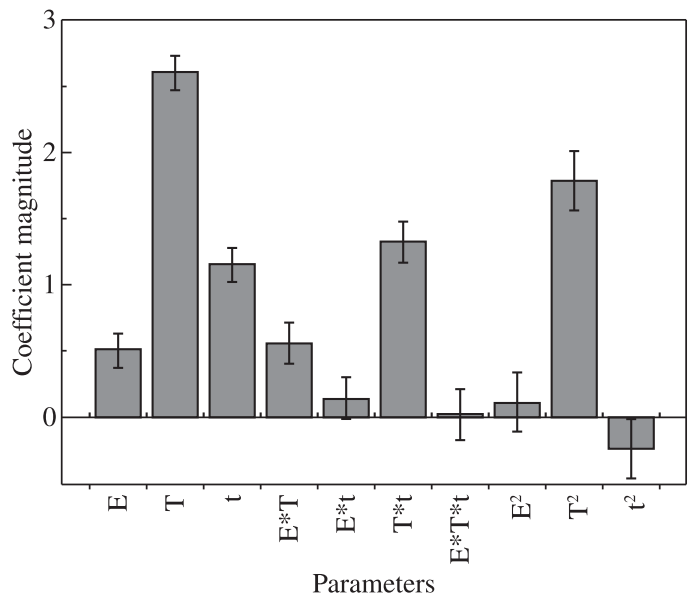

Figure 3. Coefficient magnitudes for hydroperoxide concentration, where $\mathrm{E}$ is the number of extrusions, $\mathrm{T}$ is the aging temperature and $\mathrm{t}$ is the aging time. The interaction parameters are represented by the multiplication of $\mathrm{E}$, $\mathrm{T}$ and $\mathrm{t}$. 
Carbonyl group concentration increases with temperature, but the increase in number of extrusions enhances this effect, mainly for $100{ }^{\circ} \mathrm{C}$. This group has its concentration increased with temperature as a result of and increase in kinetic formation of it: the heat provided increases the oxygen reaction rate with macroradicals ${ }^{[4-17]}$. On the other hand, number of extrusions yields more alkyl radicals to react with oxygen. But an important result is observed in Figure 6, which shows the coefficient magnitude for

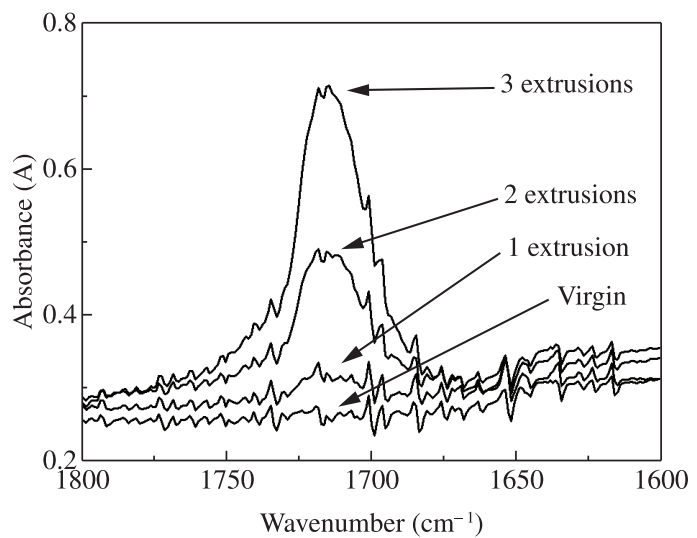

Figure 4. Carbonyl formation with number of reprocesses, for material aged at $100{ }^{\circ} \mathrm{C}$ and 300 hours.

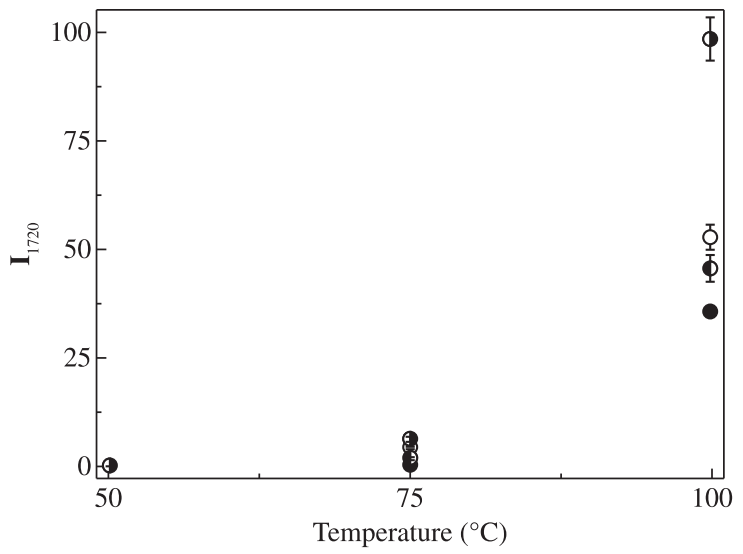

Figure 5. Carbonyl index as function of aging temperature and number of reprocessing, for 300 hours: $(\bullet)$ non processed; $(\mathbf{O})$ processed once; (०) processed twice; (O) processed three times.



Figure 6. Coefficient magnitudes for carbonyl concentration, where E is the number of extrusions, $\mathrm{T}$ is the temperature and $\mathrm{t}$ is the aging time. The interaction parameters are represented by the multiplication of $\mathrm{E}, \mathrm{T}$ and $\mathrm{t}$. a linear multiple regressions for carbonyl groups concentration. In this figure, $\mathrm{r}^{2}$ is equal to 0.93 and the regression significance was tested according to Equation 6, providing a value of 20.22, proving to be statistically significant. Temperature is the most influent parameter for carbonyl formation, followed by aging time and number of reprocessing. In spite of being the lower one, this last parameter has the same magnitude order of temperature and time. Other important result is the magnitude of interactions, which are close to the individual effects. Therefore, carbonyl group formation depends upon the interaction between parameters and not only from their isolated influence. Considering isolated effect and interactions, the number of extrusions has a great leverage on them, which means that recycled low density polyethylene are more prone to undergo oxidation in each processing step.

\section{Parameters influence on transvinylene concentration}

Transvinylene groups are formed due a disproportionation reaction, during degradation termination step. It is a result of the combination of two alkyl radicals that have free reactive sites placed in a secondary carbon. Johnston and Morrison ${ }^{[20]}$ observed that transvinylene group is direct related with carbonyl group formation, which was corroborated later by Pinheiro, Chinelatto and Canevarolo $^{[20]}$. Figure 7 shows the evolution of transvinylene group with number of extrusion.

Once this functional group rises from macroradicals recombination, the number of reprocessing leads to an increase on its concentration, considering that successive reprocessing increases the amount of alkyl radical that will react each other. The transvinylene indexes as function of number of reprocessing and temperature are shown in Figure 8, form aging time of 300 hours.

As observed for carbonyl groups, transvinylene group has its concentration increased with temperature and number of extrusions, mainly for $100{ }^{\circ} \mathrm{C}$. With all data it was performed a linear multiple regression $\left(r^{2}=0.94\right)$ to figure out the influence of parameters on its concentration. The regression significance was tested (Equation 6), providing a value of 35.68, proving to be statistically significant. Figure 9 shows that temperature is the main parameter in transvinylene formation, followed by time and number of extrusion, all of them in the same magnitude order. These three parameters have positive values, which mean a direct relation with transvinylene indexes.

The values of all interactions were also substantial, showing that not only their isolated effect are important, but their combination. Besides this, the number of extrusion has great interaction with both time and temperature.



Figure 7. Transvinylene formation with number of reprocesses, for material aged at $100{ }^{\circ} \mathrm{C}$ and 300 hours. 
Table 1. Value of coefficients from multiple linear regression.

\begin{tabular}{|c|c|c|c|c|c|c|c|c|c|}
\hline \multirow{2}{*}{$\begin{array}{c}\text { Parameter } \\
\text { E }\end{array}$} & \multicolumn{3}{|c|}{ Carbonyl $\left(1720 \mathrm{~cm}^{-1}\right)$} & \multicolumn{3}{|c|}{ Hydroperoxide $\left(3410 \mathrm{~cm}^{-1}\right)$} & \multicolumn{3}{|c|}{ Transvinylene $\left(965 \mathrm{~cm}^{-1}\right)$} \\
\hline & 5.681 & \pm & 2.5255 & 0.511 & \pm & 0.1290 & 0.602 & \pm & 0.3711 \\
\hline $\mathrm{T}$ & 17.834 & \pm & 2.5255 & 2.602 & \pm & 0.1290 & 2.511 & \pm & 0.3711 \\
\hline $\mathrm{t}$ & 10.753 & \pm & 2.5255 & 1.156 & \pm & 0.1290 & 1.677 & \pm & 0.3711 \\
\hline E.T & 7.867 & \pm & 3.0931 & 0.560 & \pm & 0.1580 & 0.820 & \pm & 0.4545 \\
\hline E.t & 4.334 & \pm & 3.0931 & 0.144 & \pm & 0.1580 & 0.499 & \pm & 0.4545 \\
\hline T.t & 15.175 & \pm & 3.0931 & 1.325 & \pm & 0.1580 & 2.375 & \pm & 0.4545 \\
\hline E.T.t & 5.983 & \pm & 3.7883 & 0.019 & \pm & 0.1935 & 0.696 & \pm & 0.5567 \\
\hline $\mathrm{E}^{2}$ & 3.132 & \pm & 4.3744 & 0.115 & \pm & 0.2234 & 0.127 & \pm & 0.6428 \\
\hline $\mathrm{T}^{2}$ & 15.445 & \pm & 4.3744 & 1.788 & \pm & 0.2234 & 2.118 & \pm & 0.6428 \\
\hline $\mathrm{T}^{2}$ & -0.667 & \pm & 4.3744 & -0.235 & \pm & 0.2234 & 0.583 & \pm & 0.6428 \\
\hline$r^{2}$ & \multicolumn{3}{|c|}{0.93} & \multicolumn{3}{|c|}{0.984} & \multicolumn{3}{|c|}{0.945} \\
\hline$\frac{M Q R / M Q r}{F_{R, r}}$ & \multicolumn{3}{|c|}{20.22} & \multicolumn{3}{|c|}{128.8} & \multicolumn{3}{|c|}{35.68} \\
\hline
\end{tabular}



Figure 8. Transvinylene index as function of aging temperature and number of reprocessing, for 300 hours: $(\bullet)$ non processed; $(\mathbf{O})$ processed once; $(\circ)$ processed twice; $(\mathbf{O})$ processed three times.

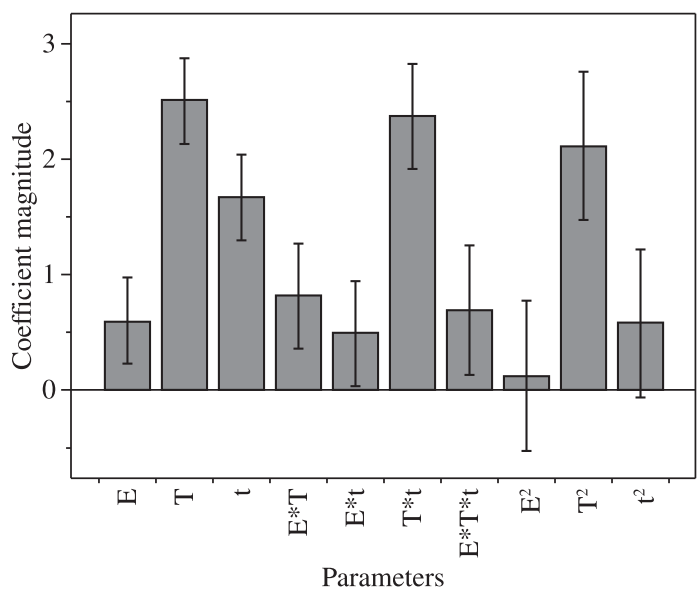

Figure 9. Coefficient magnitudes for transvinylene concentration.

\section{Comparison for the three functional groups}

Table 1 summarizes the values of coefficients due to multiple linear regression, as well as the regression coefficient and the values from $F$-test.

The codification of values during factorial design calculation allows one to compare the influence of time, temperature and number of reprocessing in the generation of studied functional groups. Considering the normalization that had been taken place, carbonyl group concentration reached the highest level among them, being more sensible to number of extrusions, time and temperature of aging than hydroperoxide and transvinylene ones. This is corroborated by the values of coefficient magnitude: all parameters have considerable effect in the formation of such functional groups, but the highest values are found for carbonyl bond.

It is found in literature that time and temperature of aging is surely related with the formation and/or consumption of functional groups. But it was also found that the number of reprocessing are supposed to be considered because of the generation of alkyl radical yielded during each extrusion step. Thus, a polymer's recycling step will lead the material to undergo more oxidation and generate more unsaturations bond not only by the action of time and temperature of exposing, but also by all recycling that it is subjected. This statement is corroborated by the coefficient magnitude of number of extrusions (E). For all functional groups it is the lowest, but has the same magnitude order. This parameter has high significance considering all possible interactions. It has great effect in the development of functional groups not isolated, but in association with time and temperature.

\section{Conclusion}

During aging experiments of recycled low density polyethylene, it was observed the formation of carbonyl, hydroperoxide, and transvinylene group due to multiple reprocessing. The increase in all functional group with number of reprocessing was attributed to the formation of alkyl radical during every recycling step. It was also observed increase in these functional groups with time and temperature of aging. Factorial design tool showed that the most influent parameter on hydroperoxide, carbonyl, and transvinylene group formation is aging temperature, followed by aging time and number of reprocessing. Although this last parameter was the less influent, it showed to be significant because its coefficients are placed in the same magnitude order. It was also verified that not only isolated effects are significant, but so do the interactions between them. All parameters were tested according to Student's t distribution and the regression itself, according to $F$ test.

\section{Acknowledgements}

To Capes, $\mathrm{CNPq}$ and Fundação Araucária for the finantial support. The authors thank Braskem for the donation of the LDPE used in this work. 


\section{References}

1. Coutinhho, F. M. B.; Mello, I. L. \& Maria, L.C. S. - Polímeros, 13, p.65 (2003)

2. Spinacé, M. A. S. \& De Paoli, M.A. - Quim. Nova, 38, p.65 (2005) http://dx.doi.org/10.1590/S0100-40422005000100014

3. Babetto, A. C. \& Canevarolo, S. V. - Polímeros, 10, p.90 (2000). http:// dx.doi.org/10.1590/S0104-14282000000200011

4. Pinheiro, L. A.; Chinelatto, M. A. \& Canevarolo S. V. - Polym. Degr. Stab., 86, p.445 (2004). http://dx.doi.org/10.1016/j. polymdegradstab.2004.05.016

5. Pinheiro, L. A.; Chinelatto, M. A. \& Canevarolo S. V. - Polym. Degr. Stab., 91, p.2324 (2006). http://dx.doi.org/10.1016/j. polymdegradstab.2006.04.005

6. El'darov, E. G.; Mamedov, F. V.; Goldberg, V. M. \& Zaikov, G. E. - Polym. Degrad. Stab., 51, p.271 (1996). http://dx.doi org/10.1016/0141-3910(95)00160-3

7. Rideal, G. R. \& Padget, J. C. - J. Polym. Sci.: Symp., 57, p.1 (1976). http://dx.doi.org/10.1002/polc.5070570103

8. Hinsken, H.; Moss, S.; Pauquet, J.-R. \& Zweifel, H. - Polym. Degrad. Stab., 34, p.279 (1991). http://dx.doi.org/10.1016/0141-3910(91)90123-9

9. Moss, S. \& Zweifel, H. - Polym. Degrad. Stab., 25, p.279 (1989).

10. Gugumus, F. - Polym. Degrad. Stab., 49, p.29 (2000). http://dx.doi. org/10.1016/0141-3910(95)00060-Y

11. Gugumus, F. - Polym. Degrad. Stab., 68, p.21 (2000). http://dx.doi. org/10.1016/S0141-3910(99)00163-9

12. Gugumus, F. - Polym. Degrad. Stab., 68, p.219 (2000). http://dx.doi. org/10.1016/S0141-3910(00)00004-5

13. Lu, S.; Buchanan,F. J. \& Orr, J. F. - Polym. Test., 21, p.623 (2002). http://dx.doi.org/10.1016/S0142-9418(01)00134-9

14. Gugumus, F. - Polym. Degrad. Stab., 68, p.327 (2000). http://dx.doi. org/10.1016/S0141-3910(00)00017-3
15. Cáceres, C. A. \& Canevarolo, S. V. - Polímeros,18, 4, p.348 (2008) http://dx.doi.org/10.1590/S0104-14282008000400015

16. Johnston, R. T. \& Morrison, E. J. - Adv. Chem. Ser., 249, p.651 (1996). http://dx.doi.org/10.1021/ba-1996-0249.ch039

17. Dostál, J.; Kašpárková, V.; Zatloukal, M.; Muras, J. \& Šimek, L. - Eur. Polym. J., 44, p.2652 (2008). http://dx.doi.org/10.1016/j. eurpolymj.2008.05.028

18. Dontula, N. \& Campbell, G. A. - Polym. Eng. Sci., 33, p.271 (1993). http://dx.doi.org/10.1002/pen.760330505

19. Cruz, S. A. \& Zanin, M. - Polym. Degrad. Stab., 80, p.31 (2003). http:// dx.doi.org/10.1016/S0141-3910(02)00379-8

20. Teixeira, S. C. S.; Moreira, M. M.; Lima, A. P.; Santos, L. S.; Rocha, B. M.; Lima, E. S.; Costa, R. A. A. F.; Silva, A. L. N.; Rocha, M. C. G. \& Coutinho, F. M. B. - Polym. Test., 24, p. 983 (2005). http://dx.doi. org/10.1016/j.polymertesting.2005.08.004

21. Aouada, F. A.; Moura, M. R.; Girotto, E. M.; Rubira, A. F. \& Muniz, E. C. - Polímeros, 18, p.126 (2008).

22. Mariatti, M.; Nasir, M. \& Ismail, H. - Polym. Test., 21, p.807 (2002). http://dx.doi.org/10.1016/S0142-9418(02)00015-6

23. De Melo, T. J. A.; Pinheiro, L. A. \& Canevarolo, S. V. - Polímeros, 20, 4, p.322 (2010).

24. Nachtigall, S. M. B.; Baumhardt Neto, R. \& Mauler, R. S. - Polym. Eng. Sci., 39, p.630 (1999). http://dx.doi.org/10.1002/pen.11452

25. Da Costa, H. M.; Ramos, V. D. \& Rocha, M. C. G. - Polym. Test., 24, p.86 (2004). http://dx.doi.org/10.1016/j.polymertesting.2004.06.006

26. Ramos, V. D.; Costa, H. M.; Rocha, M. C. G. \& Gomes, A. S. - Polym. Test., 25, p.306 (2006). http://dx.doi.org/10.1016/j. polymertesting.2006.01.002

27. Barros Neto, B.; Scarminio, I. S. \& Bruns, R. E. - "Como Fazer Experimentos", Editora da Unicamp, Campinas (2002).

Enviado: $22 / 02 / 12$

Reenviado: 01/04/12

Aceito: $23 / 04 / 12$ 